\title{
Sobre política exterior iniciando el siglo $\mathrm{XXI}^{1}$
}

\author{
CRISTIÁN PARKER GUMUCIO
}

La política exterior es un campo de acción en el plano de la sociedad internacional que ha ganado cada vez más relevancia para los estados-nacionales actuales y sus consecuencias para los ciudadanos son crecientemente influyentes en el marco de los cambios que se están observando en las sociedades en proceso de globalización, iniciando el nuevo siglo. El presente trabajo busca reflexionar, desde una perspectiva sociológica, y tomando en cuenta la experiencia chilena y latinoamericana de los últimos ańos, sobre política exterior en el contexto de los cambios que vivimos.

La política exterior puede ser definida como una política de Estado que define las relaciones y acciones que dicho Estado se propone desarrollar en el plano de sus relaciones interestatales e internacionales. Ella es una política pública de primer orden, tanto más primordial y preeminente cuanto mayor sea la influencia y la hegemonía del estado en la esfera internacional. Para las grandes potencias la política exterior define cuestiones sustanciales de la política gubernamental: para los estados pequeños su política exterior es sólo una preocupación relativa a las buenas relaciones diplomáticas que debe desarrollar con los estados centrales de los cuales depende y con los cuales interactúa primordialmente.

Toda política exterior se desarrolla en forma prioritaria por medio de la actividad diplomática. Ella no es la única actividad que sirve a la política exterior y en la trama compleja de interacciones en la sociedad internacional de hoy ello es más evidente, pero nadie puede desconocer que la diplomacia sigue siendo un medio privilegiado de desarrollo de la acción del estado en el plano internacional en sus diversos ámbitos, bilaterales, multilaterales, regionales, hemisféricos y globales.

Tanta mayor la importancia de la formación de los diplomáticos de hoy cuanto mayor la exigencia y los desafíos de una sociedad cuyo proceso de globalización

1 Versión levemente modificada de la Clase Magistral dictada en la Inauguración del Magister en Política Exterior, Programa desarrollado por la Universidad de Santiago de Chile en convenio con la Academia Diplomática de Chile, "Andrés Bello", CENI, Santiago, 19 de mayo de 2004.

2 Sociólogo, Doctor en Sociología, Profesor Titular, Universidad de Santiago de Chile, Investigador Titular, Instituto de Estudios Avanzados, USACH, Director del Programa de Magíster en Política Exterior. 
transforma cuestiones que históricamente y estructuralmente se daban por sentadas hasta no hace dos décadas en la época de la post guerra y de la guerra-fría. El reclutamiento y la formación profesional, así como el perfeccionamiento y especialización de los diplomáticos tiene su correlato en servicios exteriores cuya institucionalización y profesionalización es cada día más exigente en el mundo actual.

En efecto, la actividad diplomática ha sido desde los inicios del Renacimiento - con las ciudades estado italianas- una actividad cada vez más especializada. En la medida en que los estados necesitan representantes permanentes de sus gobiernos en los estados e instituciones internacionales con los cuales ha entablado relaciones o pretende llevarlas a cabo, se requiere personal del llamado "servicio exterior". Este incluye a las personas que son de la carrera diplomática, incluyendo a embajadores, enviados y funcionarios asignados en el extranjero. Aun cando sabemos que los gobiernos también nombran embajadores de su confianza que no son de carrera diplomática.

Por ello, cuando hablamos de la actividad diplomática estamos hablando siempre de actividades oficiales de un Estado. En el contexto de las relaciones internacionales hacia fines del siglo XX - tendencia acentuada durante esta última década - la actividad diplomática de los estados y de los organismos internacionales ha sido crecientemente acompañada de la actividad "paradiplomática" de entidades paraestatales, o subnacionales (regionales o locales), o simplemente por representantes de organismos no estatales (como empresas multinacionales, organismos no gubernamentales internacionales, etc.)

En este marco, las relaciones internacionales cubren ese amplio campo de las relaciones en la sociedad internacional que ya no se restringen a las relaciones bilaterales o multilaterales entre estados e incorpora a un sinnúmero de actores de la sociedad internacional creciente.

Si las relaciones internacionales concebidas bajo su clásica definición de "diplomacia" (comprendidas desde la historia diplomática y el derecho internacional) hace ya mucho tiempo que dejó de tener pertinencia, la propia actividad diplomática de inicios del siglo XXI ya no es la misma de antes, dadas las nuevas exigencia y desafíos de los nuevos escenarios internacionales.

Es en este marco de transformación de la función diplomática que debemos reconceptualizar la política exterior. Es claro que política exterior no es sinónimo de función diplomática y mucho menos de "relaciones internacionales". Dado que este último término refiere a un amplio campo de actividades en la sociedad internacional y no se restringe a las relaciones entre estados. Muchas veces incluso se habla del ejercicio de una "función pública internacional" materializada en organismos internacionales, ONG's e instituciones financieras multilaterales; profesiona- 
les $y$ funcionarios que ejercen tareas o funciones relacionadas con la actividad internacional, ya sea desde entornos públicos o privados.

Es decir, si las relaciones internacionales abarcan una amplia gama de actividades, la actividad diplomática que está referida a la acción de los funcionarios del servicio exterior, si bien se ejerce en los más variados campos y temas, no es sino una actividad de función pública internacional específica: referida al Estado y a la política exterior de los Estados. Por ello el concepto de política exterior está estrechamente vinculado al concepto de función diplomática, $y$, aun cuando la realización de la política exterior de un Estado se da en el plano de las relaciones internacionales, y por medio del ejercicio de la función diplomática, nunca debiera llegar a confundirse estos tres términos.

La ciencia social que aborda a las relaciones internacionales lo hace desde una postura positiva. Este mismo enfoque es admisible respecto a la política exterior, a condición de no olvidar que la naturaleza de ésta última es de tipo normativo. Esto es, a las consideraciones más menos neutras - desde la objetividad metodológica de la ciencia social - que hacemos acerca de las relaciones internacionales, debe sumarse un doble ejercicio teórico, reflexivo y metódico: no puede abordarse científica y académicamente a la política exterior sino a condición de la extrema rigurosidad explicativa y metodológica, pero tampoco puede comprenderse significativamente a la política exterior sino en el marco de las definiciones programáticas de dicha política que se enmarcan en determinados principios y valores y que por ende, deben ser interpretados y analizados a la luz del paradigma que informa dichas políticas de Estado. Por cierto, estamos hablando del análisis político y no de las opciones de políticas en materia contingente que no caben en el área del trabajo académico que analizamos.

Es claro entonces que estamos ante una materia en proceso de cambio. No sólo es el contenido de la política exterior de los Estados el que se ha visto modificado a raíz de esos dos acontecimientos que han marcado los últimos quince años a la sociedad internacional: a saber la caída del Muro de Berlín (1989) y los ataques del 11 de septiembre de 2001. Es también la propia naturaleza y estructura de las relaciones internacionales o, dicho de otro modo, son las profundas mutaciones de la sociedad del siglo XXI lo que modifica las condiciones de posibilidad del ejercicio de políticas en el plano exterior para los estados.

Hasta la década de los 70 los temas vinculados con la seguridad internacional dominaron los estudios, desde esa fecha el peso de la economía en las relaciones internacionales creció y con ella el interés por su estudio. En efecto, la política exterior ya no estuvo dominada por el tema militar y de la paz, sino que por el 
comercio internacional, la cooperación y el rol de los organismos internacionales en ése ámbito, tales como el Banco Mundial o el Fondo Monetario Internacional (FMI).

En la actualidad muchos fundamentos del sistema interestatal están siendo tensionados y los organismos internacionales - que sugieran en la post guerra, como el sistema de NNUU - sufren una crisis endémica a pesar de los avances de los procesos de integración en diversas regiones. El avance de las tecnologías de la comunicación y de la información, las nuevas formas de producción, comercio, finanzas y circulación, las nuevas formas de organizaciones legítimas (organismos internacionales, empresas transnacionales) e ilegitimas (como el narcotráfico y los grupos paramilitares y terroristas) y las transformaciones en las normas internacionales, parecen estar afectando la idea de la integridad territorial y la soberanía nacional (esto es, la autoridad absoluta de los gobiernos sobre los asuntos nacionales). Los medios audiovisuales (televisión, radio y telefonía) e informáticos (Internet) parecen borrar los límites entre los estados, generando nuevos espacios de fronteras donde nuevas convivencias ciudadanas se comienzan a gestar: ya no atadas a la territorialidad, mezclando culturas y extendiendo las relaciones internacionales. Los medios de comunicación llaman la atención de cuestiones y acontecimientos lejanos que ahora se hacen presente en vivo y en directo en el living de la casa. Temas que ayer afectaban solamente a la opinión pública de un país y sus vecinos ahora se convierten en controversia mundial: violación de derechos humanos, trata de personas y especialmente de mujeres y niños, crímenes contra la humanidad, graves acontecimientos que agreden al medio ambiente, situaciones políticas que atentan contra principios democráticos, etc. Muchas fronteras y territorios han cambiado o están cambiando. Algunos países se integran a unidades mayores como en la Unión Europea y otros se han desmembrado como la ex Unión Soviética.

Los cambios están alimentando un debate entre los especialistas acerca del propio sistema interestatal. ¿Está en crisis el Estado-nación? ¿¿Sobrevivirá el sistema internacional basado en él? Hay voces que afirman que los Estados con identidad cultural distintiva, sus fronteras y sus gobiernos han pasado a ser una reliquia que pronto perecerá. La economía internacional estaría socavándolo. Ella sería la que definiria las relaciones internacionales, lo cual exige replantearse las antiguas fronteras y repensar los límites que surgieron con la modernidad, dando pie a una mayor colaboración.

Las urgencias del presente que requieren de la cooperación, y más todavía, las exigencias y prerrequisitos de las nuevas tecnologías de la comunicación y de la información, parecen estar borrando las antiguas fronteras. Pero la persistencia de los estados-naciones y el reclamo de muchos pueblos y naciones por alcanzar dicho status en el concierto de las naciones, así como la persistencia de los aparatos bu- 
rocráticos y militares, no auguran la desaparición del estado como soñaran los utopistas desde el comunismo hasta el liberalismo anarquista. El sistema interestatal está en una profunda mutación pero no parece haber llegado el momento de su transformación radical, lo que asegura, ciertamente, por un largo período todavía, la vigencia de la política exterior y de la función diplomática tal como la conocemos en el inicio del siglo.

Lo que no está en duda es que la política exterior ha estado sufriendo profundas modificaciones.

\section{Principales cambios en las lineas de fuerza del estudio de la politica exterior}

Entre las grandes líneas de fuerza de los cambios suscitados en estos últimos decenios en cuanto a los principios que guían a la política exterior de los estados se cuenta: el paso de una política exterior guiada explicita o implícitamente por la geopolítica a una política guiada explícitamente por lo que podríamos llamar una "demo-política". Dinámica acompañada en paralelo, (articulada o en forma contradictoria) por el tránsito de una política exterior estatocéntrica a una política exterior eco-política.

En el período de la post-guerra fría estamos presenciando no sólo un cambio de escenario. El 11 de septiembre del 2001 no confirma una nueva coyuntura internacional sino que es, en realidad, el reflejo de nuevas estructuras y relaciones que están naciendo en la sociedad global que emerge en este siglo. A las dinámicas interestatales e internacionales se suman ahora de manera decisiva y cada vez más relevantes las dinámicas post-nacionales (de las cuales nos hablaba Habermas) y las dinámicas subnacionales (de regiones internas, locales, étnicas, religiosas, nacionales no estatales, etc). Y las contradicciones de la sociedad internacional - que no pueden ya ser interpretadas de manera tan esquemática a la Huntington como choque de civilizaciones ya no se reflejan exclusivamente en el plano inter - nacional sino que repercuten dialécticamente a nivel global y local con esas réplicas insospechadas que tienen los terremotos geo-culturales del presente. No de otra manera puede comprenderse el efecto boomerang que tiene el abuso de los prisioneros iraquíes por parte de las tropas norteamericanas en la política interna de los Estados Unidos; o la inmediata repercusión del atentado en Madrid sobre el cambio de gobierno en España.

En realidad se ha pasado - si me permiten emplear esa tipología - de una política exterior guiada por los códigos de la geopolítica hacia una política exterior guiada por los códigos de la demo-política. Ya Aron nos remarcaba que todavía en la época de la guerra fría y hasta bien avanzado el siglo XX el tema de la guerra y la paz era el que dominaba las relaciones internacionales. Las diversas políticas seguidas por las potencias en el mundo bipolar se enmarcaban, en realidad, por principios derivados 
de los hegemonismos que no eran sólo ni primariamente ideológicos (capitalismo contra comunismo) sino, en el fondo, geopolíticos (hegemonia norteamericana vs hegemonía rusa). Con el derrumbe de la URSS y la caída del muro de Berlín, una nueva sociedad internacional emerge. No más estable como se había esperado y habían soñado los que ansiaban la caída del comunismo, sino una sociedad mucho más inestable e insegura donde los conflictos locales y regionales, las guerras locales y los grupos paramilitares y caudillos, narcotraficantes, y grupos mafiosos, la corrupción nacional e internacional, etc. amenazan la seguridad de los pueblos.

Es efectivo que el ideal democrático es un principio que ahora guía la política exterior, luego del derrumbe soviético y del fin de los regímenes militares autoritarios en América Latina. Y por lo mismo, es cierto que las acciones de mantenimiento o imposición de paz, están, desde 1992 guiadas por la búsqueda del restablecimiento de regimenes que respeten los derechos humanos, que restituyan los Estados de Derecho y que avancen en el establecimiento de democracias. La noción de "construcción nacional" en estos contextos puede ser riesgosa si con ello se vuelve a aplicar el viejo principio del perimido modelo del Estado- nación moderno, hegemónico y monocultural.

Pero una de las cuestiones de mayor relevancia que tiene este giro, a mi parecer, es que el principio estructurante del pensamiento geopolítico, a saber la Seguridad del Estado en el marco de una soberanía que privilegia el principio territorial, se está avanzando hacia el reconocimiento más decisivo de un pensamiento fundante de la demo-política a saber, la soberanía popular como fundante del Estado. Cuando se privilegia la soberanía territorial se acentúa el principio de la fuerza y de los límites espaciales de dicha fuerza; cuando se privilegia la soberanía popular se acentúa el principio de ciudadanía y de las condiciones de participación que respeten a las personas y sus derechos, en el marco de un sistema normativo que tiene que compatibilizar la juridicidad nacional con el consenso de una juridicidad internacional en formación y que, en todo caso, debe guiarse por sólidos principios éticos. Es decir, y lo hemos presenciado muy claramente en nuestro país, el tránsito del principio de la Seguridad del Estado al principio del imperio del Estado de Derecho ha modificado de manera sustancial la definición y la proyección de la política exterior. Y conste que esto no sólo ha sucedido en nuestro país: ello es un fenómeno que se puede observar en el terreno internacional con la diversidad de matices en las diversas realidades y que admite una visión global.

Este giro en la política exterior "postnacional" en una sociedad en la cual todavía el estado-nación, a pesar de sus cuestionamiento y sus crisis, sigue siendo la realidad preeminente en las relaciones internacionales, no está exento de complejidades y contradicciones que no vienen al caso detallar pero que requerirían un análisis por cierto muy amplio y pormenorizado. 
No es solo el tránsito de la geopolítica hacia la demo-politica lo que marca el inicio del siglo XXI. ( $Y$ en realidad estamos hablando de acentos ya que los principios geopolíticos no han dejado de operar) - es, por otra parte, el tránsito del predominio del Estado hacia el predominio del mercado en el pensamiento político programático lo que también está afectando y, de manera más relevante todavía, incidiendo directamente en la política exterior de los estados. Para seguir con mi tipología neológica: se ha pasado de la estato-política a la eco-política (como veremos esta última como nomos (eco-nomos) en un extremo o como logos (eco-logos) en el otro).

En la medida en que dejamos atrás a las formas sociales propias de la sociedad industrial moderna y entramos e la sociedad post-industrial, o sociedad de la información y del conocimiento ("sociedad red" analizada por Castells), estamos abandonando el estatocentrismo del modo de producción: capitalista o socialista, de los países centrales o periféricos: no es sólo el Estado centralizado que se derrumbó con el Muro de Berlín: también lo hizo el Estado de Bienestar capitalista y el Estado de Compromiso en los países latinoamericanos. El tan comentado neoliberalismo como quiere que se evalúe y se aprecien sus modalidades - tuvo el impacto de reivindicar al mercado como principio regulador de la economía y de paso desplazó al estado - con mayor o menor intensidad- de dicha función.

Ahora bien, el Estado no ha desaparecido. Para nada. Y precisamente lo que se discute es cómo su permanencia - más allá de los procesos de descentralización y regionalización subnacional y/o de integración supraestatal - reside precisamente en tres funciones: defensa, exterior e impuestos. La política exterior es prerrogativa del estado nacional pero ¿y qué sucede cuando las regiones pasan a definir un campo muy amplio de relaciones internacionales? Bueno, es que dependiendo del grado de descentralización y de regionalización dichas entidades subnacionales también forman pare del Estado. ¿Entonces la política exterior ya no es función exclusiva del Estado central? Estas interrogantes se tornan más acuciosas en la medida en que la agenda de las políticas exteriores están dominadas cada vez más por temas del campo económico: negociaciones comerciales, tratados de libre comercio, integración a mercado regionales, etc. y menos por temáticas propiamente políticas o clásicamente diplomáticas.

Lo cierto es que durante el predominio del principio estatal de regulación, incluso los temas económicos estaban bajo las definiciones de la política pública (incluso en regímenes capitalistas avanzados) lo cual - bajo el influjo de la dinámica propia del Estado de Bienestar - aseguraba que los temas de política interna predominaran por sobre la política exterior en la agenda pública nacional. Con la apertura comercial y la disminución de los proteccionismos, la política exterior se vuelve hacia la economía internacional, y con la mayor interdependencia económica, financiera y comercial las repercusiones de la dinámica internacional en la sociedad nacional (y 
lo vemos hoy con el precio del petróleo y del gas) se hacen más evidente, haciendo más visible y relevante la política exterior para el ciudadano medio.

En síntesis, el resultado de esta profunda transformación nos permite afirmar que con predominio del Estado tenemos mayor relevancia de la política interna; en cambio, con predominio de la economía internacional globalizada tenemos mayor relevancia de la política exterior. Por ende, no es extraño que las funciones del diplomático de hoy ya no sean las de antaño. Ahora el diplomático debe actuar en un campo de múltiples desafíos: las principales acciones diplomáticas residen en las negociaciones relativas al comercio y al libre mercado internacional.

Pero, como hemos afirmado, las exigencias de la demo-politica impiden que la eco-política dominada por la eco-nomía monopolicen las políticas exteriores y las funciones diplomáticas del presente. De aquí una natural tensión observada hoy en las definiciones de la política exterior, entre los énfasis en las relaciones económicas internacionales que arrastran pragmáticamente a la política, y la exigencia de consideración de cuestiones propiamente políticas cuyo olvido puede ser muy negativo para el Estado y sus interacciones en el plano global.

Hay todavía otra eco-política que contribuye a morigerar el monopolio de la economía en las relaciones internacionales de hoy. Nos referimos a la eco-logia. Se trata de recordar aquí el paso progresivo que presenciamos desde una economía clásica centrada en la producción (el industrialismo) a una economía ecológica centrada en la conservación y la sustentatabilidad (energía limpia y renovable, producción no contaminante, sustentabilidad ambiental).

En efecto, a la lógica productivista y, en ocasiones, depredadora de la economía contemporánea le sale al paso un principio de limitación que proviene de la lógica interna de los ecosistemas. Al eco-nomos, es decir, al principio de regulación normativo del oikos contemporáneo, se le opone un eco-logos, es decir un principio de autorregulación de los biosistemas. La preocupación por el medio ambiente, y la biodiversidad ha dejado de ser un tema romántico y se está planteando ahora como una condición de posibilidad del desarrollo futuro, es decir, la sustentabilidad ambiental es condición indispensable para la sustentabilidad del desarrollo y ello, por cierto, no puede ni debe descuidarse en la política exterior de los estados.

Pero la eco-logos, no sólo puede interpretarse desde el punto de vista de los ecosistemas naturales: la diversidad cultural del planeta es una de sus riquezas humanas más relevantes y forman parte de su biodiversidad. De aquí que la sustentabilidad cultural de la humanidad requiere de respeto a las identidades étnicas, religiosas y nacionales y a la promoción de una convivencia inter y multicultural donde la cultura de la paz se logre mediante la constante negociación pacifica y 
eficaz de conflictos (reconociendo que muchos de ellos son de naturaleza compleja e inevitables).

Estas son algunas de las cuestiones que conforman, a nuestro entender, un marco conceptual y analítico que posibilita la comprensión del proceso de cambios, orientaciones y tensiones que vive hoy la política exterior en Chile y los países latinoamericanos. Se trata, por cierto de un análisis tipológico - ni histórico ni sociopolítico - que repara mucho más en la lógica o líneas de fuerza que orientan el conjunto de acciones sociales que conocemos como "política exterior" de los estados en el contexto de la globalización actual.

Dependerá de la estructura sociopolítica, tradición histórico-política, campo político y partidos políticos predominantes y coyuntura política específica, el énfasis que se otorgará a cada orientación: o bien lo central de la política exterior estará constituido por lo eco-nómico o bien por lo demo-político, pero dos cuestiones son decisivas: a) las motivaciones geopolíticas orientadas por la Seguridad del Estado tal como eran entendidas bajo la guerra fría - ya no están vigentes; y b) las nuevas estructuras de la sociedad capitalista global emergente en los inicios del siglo XXI, si bien atravesadas por factores vinculados la información y comunicación, establecen como prerrequisito la atención de lo económico-financiero-comercial. El análisis de la política exterior de cada estado en cada momento histórico nos revelará en forma específica cual o cuales serán los principios orientadores que estarán guiando las decisiones fundamentales de política. 